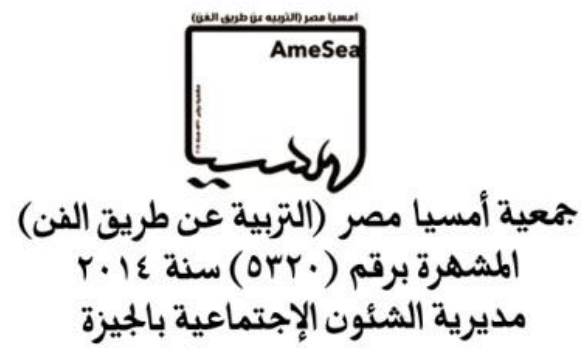

التعبير بين الددس والتقنين في فن التصوير

إعداد

أ.دد/ عادل محمد ثروت

أستاذ الرسم و التصوير بكلية التربية الفنية - جامعة حلوان

\title{
$r \cdot 10$
}


التعبير سلوك إنساني يأتي نتيجة دافع يكمن في النفس وهذا السلوك لا يخضع للتكوين الداخلي فقط و إنما يخضع أيضا لتلك العو امل الخارجية من البيئة المحيطة بالفنان و المؤثزات الاجتماعية من حوله و العلاقات الإنسانية التي يتفاعل معها و المسائل الأخلاقية التي يتعايث بها مع الآخرين و التي تتفاعل معه وتؤثز فيه وتكون لدية الرصيد الإبداعي وكلها عو امل لها أثزها في إيجاد الدوافع وتحقيق الانفعالات ، و هو ما دعي الفنان في كثير من الأحيان إلي ان يرتفع إلي مستوي التعبير عن مضمون العمل الفني محاو لا ان يستتبط صور تخرجنا من عالم الثكل الطبيعي إلي الحقيقة والانتقال من صورتها العرضية إلي أثنكالها الجوهرية أو ما اسماه عز الدين إسماعيل " تصوير ما يمكن "نسميته بالموضوع الداخلي "

و السلوك ذو الطبيعة التعبيرية يؤدي إلي الإبقاء علي الطاقة الانفعالية لدي الفنان وهو هنا يتحكم فيها ويوجهها إلي البناء و القيام بمهام التحويل و التزكيب و الاختيار و التحكم في النظم وتتسيقاتها من اجل تحقيق الإبداع تحقيقا موضو عيا وهو ما يؤكده جون ديوي في ان "هذه الحالة ـ الاختيار و التنظيم تعد تعبير ا كما ان الانفعال الذي يرتبط بالموضوع المترثب علية أو الذي يتذاخل معه هو في صميمة انفعال جمالي " يصنعه الفنان بالطريقة أو الأسلوب الأدائي المناسب فقد يكون عن طريق الاستخدام الو اقعي للمفردات و العناصر أو بالتخلص من الأشكال الواقعية للتعبير عن المضامين و الأفكار و المعاني وما في أعماق الأشكال من حقائق كامنة تخالف أو تتاقض الحقيقة البادية للعيان وتكون أكثز دلالة عليها من خلال التوصل إلي إبداع رموز متحررة من تمثيل الو اقع ليعلق أهمية علي لمسات الفرشاة لإبداع صورة أصلية من الأفكار و الإشكال المجردة محملة بتعبير ات ومعان خاصة ولقد كتب فان جوخ " ان الانفعالات هي من القوة بحيث ان المرء ليعمل دون ان يدري انه يعمل " و هو هنا يعني ان التعبير يظهر تلقائيا والتلقائية هنا ثمرة طويلة من النشاط ، فيحول الفنان الانفعال إلي وسائط تؤثز علي المادة الخارجية فتتحول إلي عمل فني وبذلك يعد التعبير تتظيما غير مباشر يحقق الانفعال بارتباط عضوي بينة وبين ما ينتقيه الفنان لهذا التتظيم الفني، إنها أحاسيس وعو اطف وخبر ات تتنظم حوله سائر مقومات العمل الفني كما انه الدلالة النفسية داخلة وهو العلاقة الحية بين الفنان و الموضوع وهو ينعكس علي الأعمال الفنية فتتصف كل منها بتعبير جمالي يختلف عن الأخر وفي كل تعبير يمكن ان نميز بين الموضوع المعروض بالفعل والطاقة الانفعالية التي استخدمها الفنان للتعبير عن الموضوع الموحي به ثم الفكرة اللاحقة والانفعال أو الصورة المثارة أو الثئ المعبر عنه كذلك يرتبط التعبير بالتز ابط والتداعي فهو يرتبط في ذهن الفنان بتجاربه السابقة وهي 
ارتباطات داخله في اللاشعور لذلك لا يوجد اتفاق عام علي السمات التعبيرية للموضوعات وبذلك

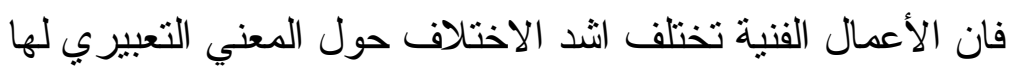

وفي المعرض الحالي قام الباحث بالتعبير عن الانفعال الحدسي المباشر عن طريق الارتجال

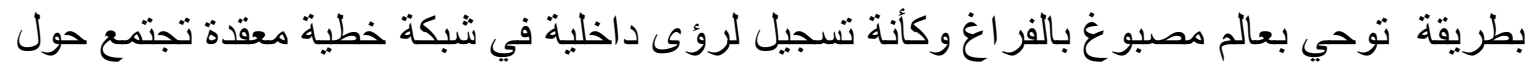

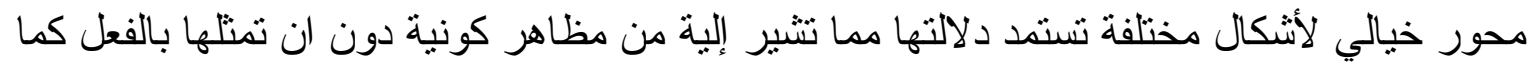
إنها تأخذ في كثير من الحالات وبشكل غير إرادي عوالم موحية تعتمد علي استخدام ضربات

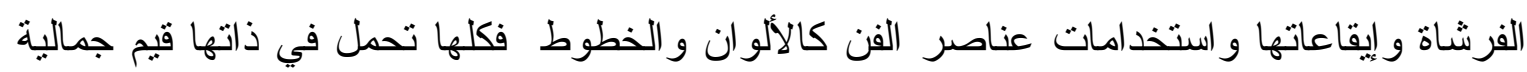
وتعبيرية ، فيعبر الباحث من خلالها عن موضوعات فنية لا يستخدم فيها الثنكل الثابت المتعارف علية بل يلجأ إلي رموز خاصة ذات معني يقصده ليصل إلي إبداع علاقات جديدة نوحي لنا بالعديد

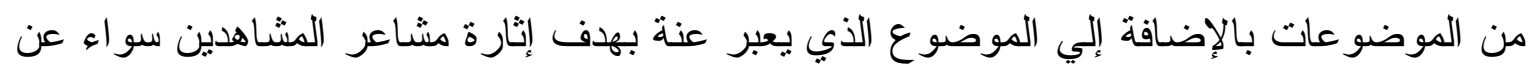
طريق الناكيد علي قيم وعناصر الفن والتي تضفي علي العمل الفني الإحساس بالجمال ، و الجمال هنا اختلف من وجه نظر الباحث فلم يعد هو جمال الثنكل بل هو جمال الفكر والمضمون ، فنجد

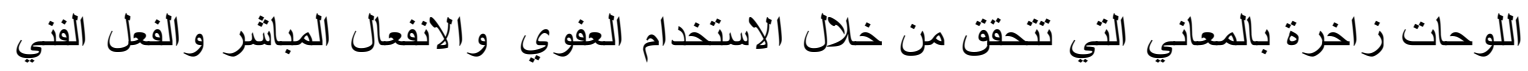
علي مسطح اللوحة والذي يصل في بعض الأحيان إلي استخدام المجموعات اللونية في مساحات

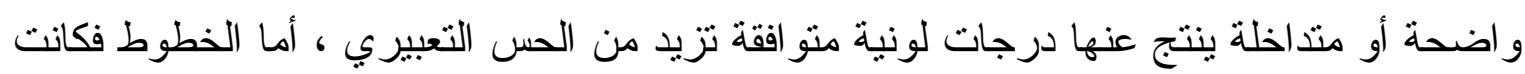

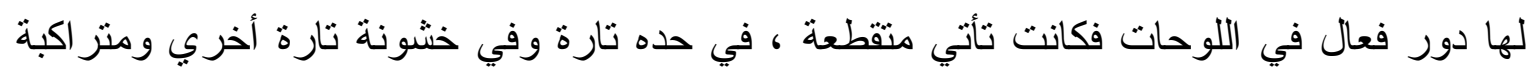

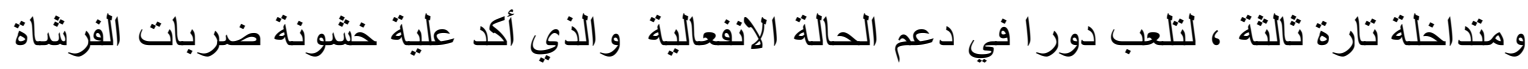

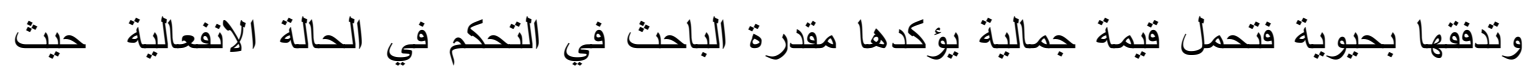

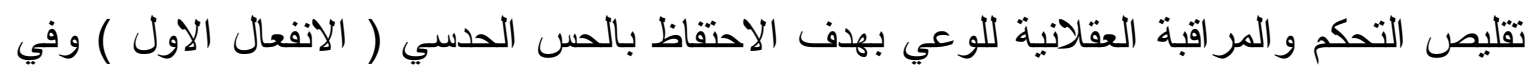
الدقابل قد يلجأ الباحث إلي عناصر المر اقبة العقلية والتحكم الأدائي و الثقني في رسم بعض الأجز اء التهاء

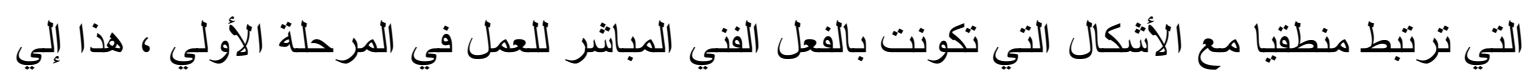

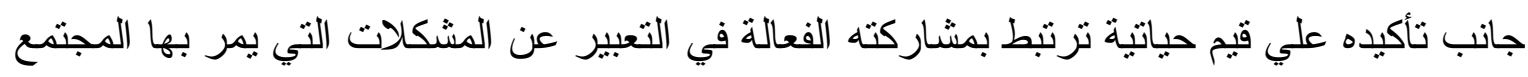

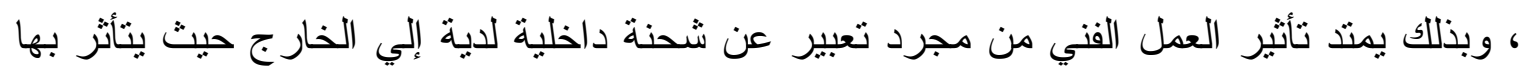

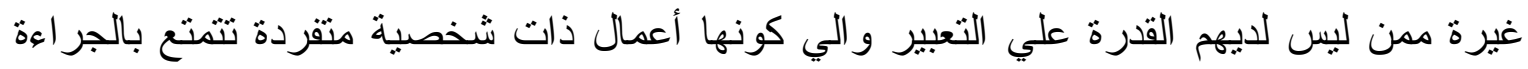

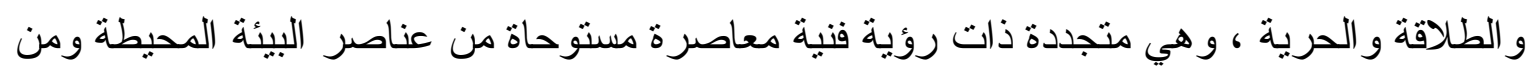

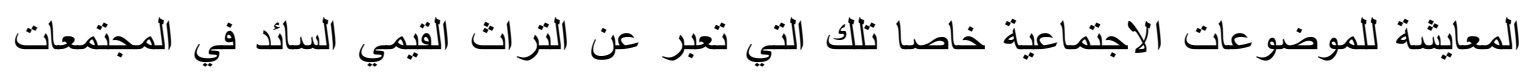


1 - عملية اختبار المادة و الثقنية : وهي وسيلة لبلوغ التكامل الفني وهي ليست هدفا بذاتة أو

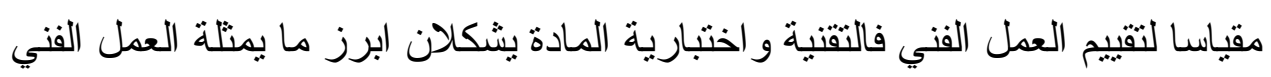
r- الفعل الفني المباثر : وهو يتطلب تقنية خاصة تكون المنطلق الاساسي لتتكيل بنية العمل

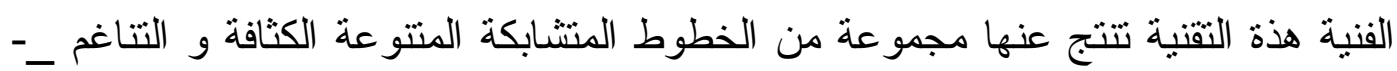

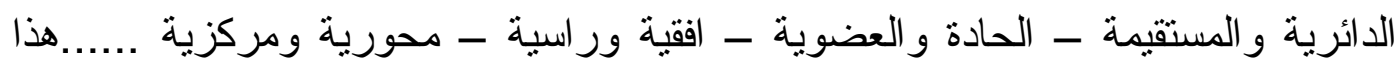

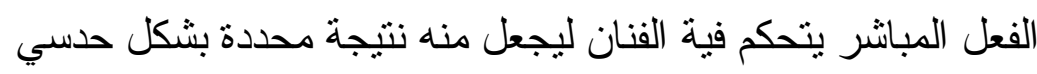

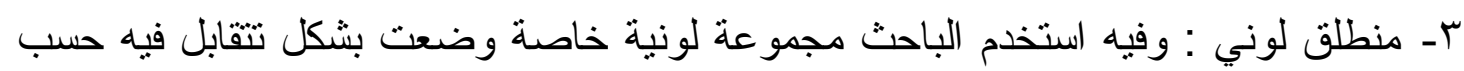

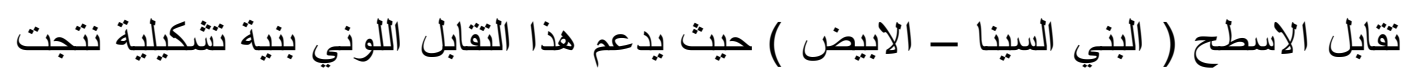

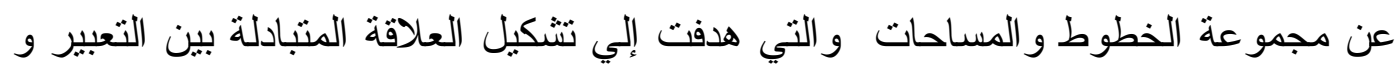
الفعل الفني المباثر

المنطلق الفكري

اعتمد الباحث علي دراسة طبيعة المادة وخصائصها وايضا تقتين الصدفه فما يدفع إلي التفكير و التامل والاكتثاف من خلال عمليات التجريب ، والحس المباشر - الانفعال - الاملاءات الانفعالية للتعبير و التي تعتمد علي الصدفة واختبارية المادة وهو ما لا تتتفي معه المر اقبة العقلانية

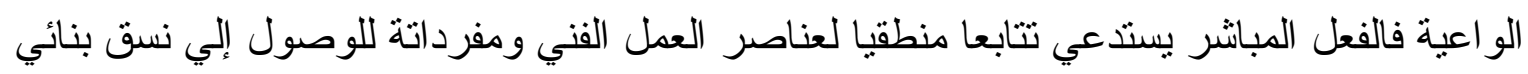
يتميزبوحدة عضوية للوصول إلي التعبير المباثر المعتمد علي الاملاء المباشر للحالة الانفعالية

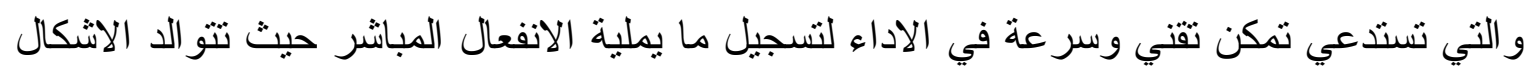

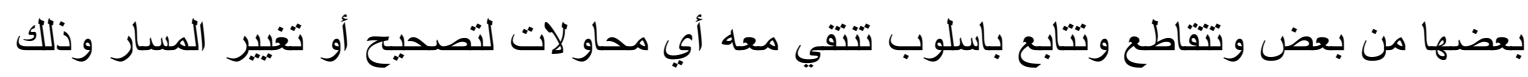

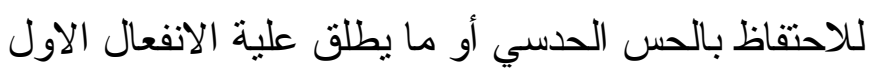

\section{منطلق وحدة النسق البنائى}

يهذف الباحث في المعرض الحالي إلي بناء اعمال فنية ذي هيئة جمالية موحدة تتسم بنسق بنائي انفعالي حر يجمع بين تلقائية التعبير المباثر و المر اقبة العقلية الواعية و التحكم في النظام الناتج من فئه

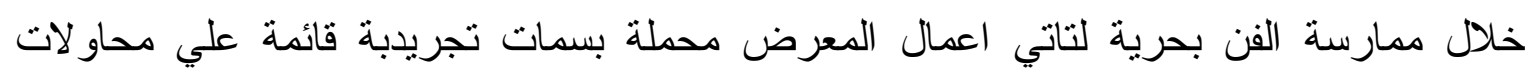
تجريبية لاكتشاف مشاكل بنية اللوحة إلي جانب تحميلها مجموعة من الخصائص الموحدة التي لمئل 
تميزها كمجو عة تتكيلية لها طابع تشكيلي خاص قائم علي المضمون التعبيري الذي نستشعره في جميع اللوحات وفي كل لوحة علي حده

علي ذلك اتجة الباحث إلي تحليل الاعمال الفني من خلال تقسيمها إلي مجموعات لها طابع بنائي منقارب في النسق البنائي و الادائي التي

\section{المجموعة القنية الاولي}

وفيها توصل الباحث في العمل لبنية تثكيلية متحررة ليصبح الأداء الانفعالي المباثر هو هدف في

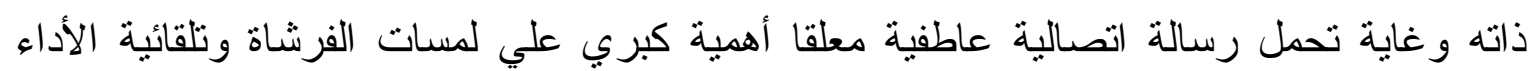
فالثكل و اللون الخالص و الخطوط المنباينة هي أثنكال تكتسب حيويتها من قيمتها الارتباطيه وطاقتها

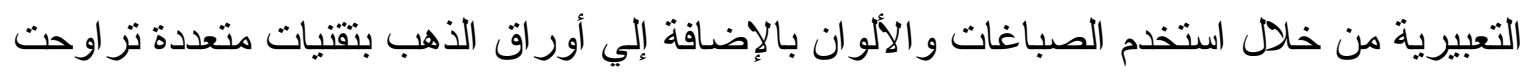
بين حقن الصباغات علي التوال مباشرة أو علي سطح اور اق الذهب بطريقة دائرية أو رأسية و الققية

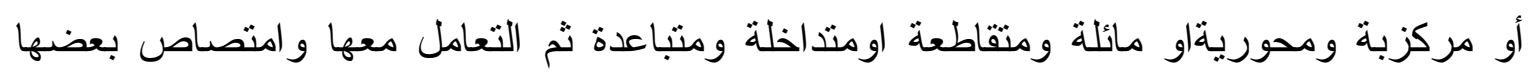
و از الة البعض الاخر بينما يترك البعض ليسيل علي السطح لينتج انشالا جديدة متداخلة نوحي للفنان

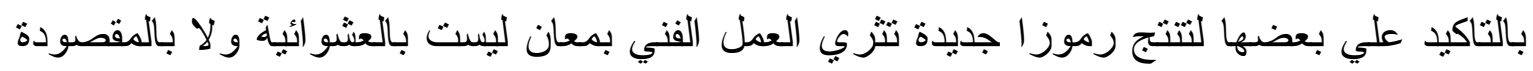

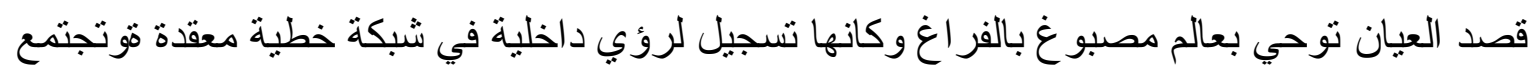

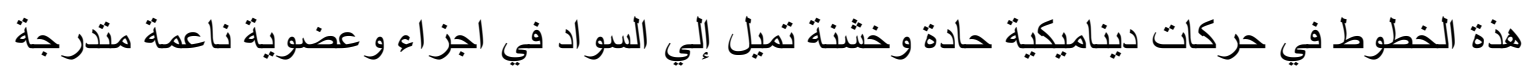

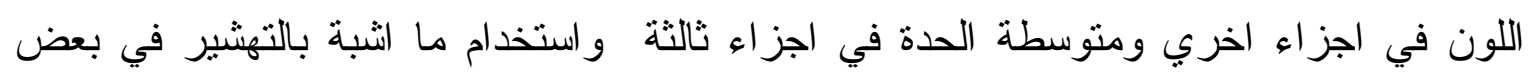
الاجز اء بحيث تتقتت العلاقة الصارمة بين محتويات الثكل ومحتويات الارضية في تبادل للاهمية

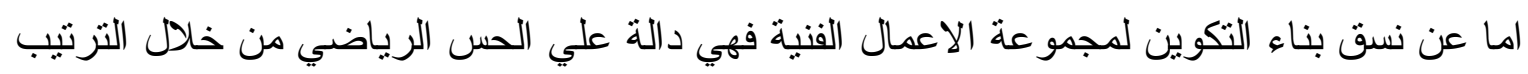
و التتظيم المميز للعناصر الفنية الناتج من حركة الخطوط و المساحات المحصورة بينها أو القائمة بذاتها وقد ادت الخطوط الافقية الغالبة علي الاعمال الفنية بالاضافة إلي الخطوط الدائرية إلي لفئ

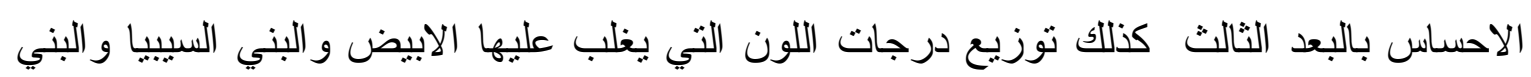

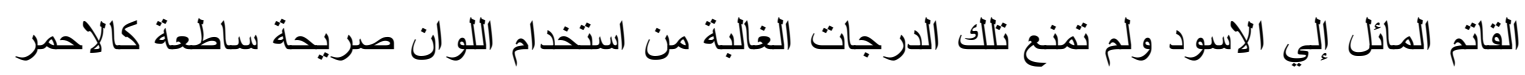

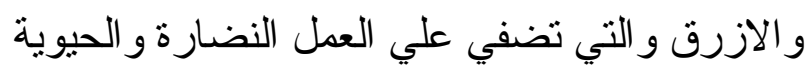

ولم يتخلي الباحث عن العناصر و المفردات التثكيلية المميزة من عناصر كتابية أو الوحدات الثعبية كالعروسة و النخلة التي تم استخدامها بتلخيص وتبسيط يتتاسب و الاستخدامات الخطية كذلك استخدام

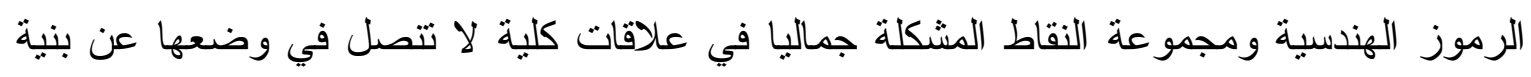
الاعمال 


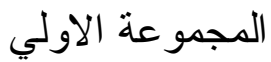

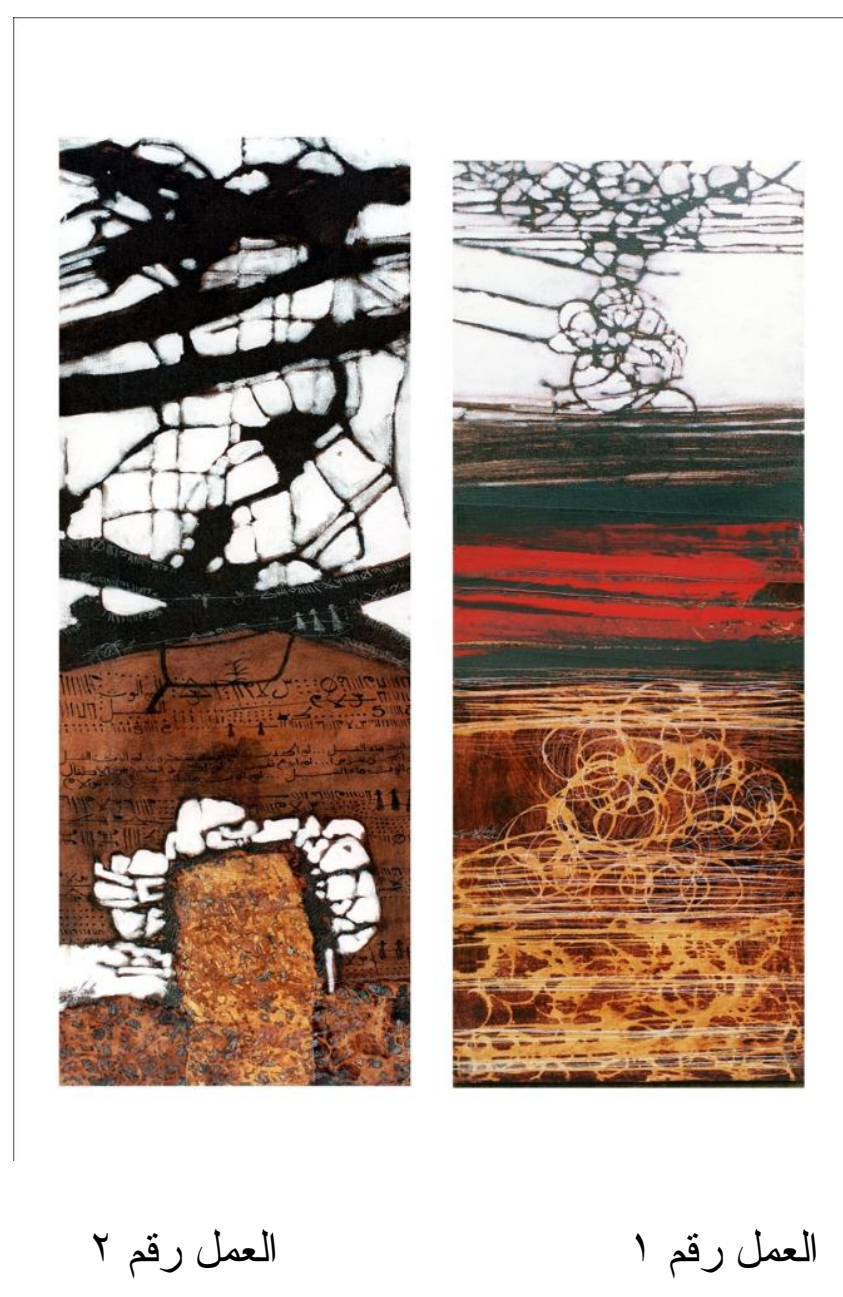

العمل رقم 1

نري فية تتوع استخدام الخط ما بين الدائرية و الافقية وتوزيعها بطرقة متسقة وفي تتظيم منو افق مع الانفعال الادائي لوضع الخط حيث تجمعهم وحدة منتظمة متكاملة تجمع في توافق بين التلقائية و الحس الرياضي في نتكيل العناصر المستخدمة والذي يؤكدة وضع درجة اللون الاحمر في لئ منتصف اللوحة في حجم يتتاسب مع اعلي و اسفل اللوحة

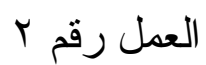
وفية العلاقة بين المتناقضات التعبير التلقائي الحر و تتظيم التكوين الرياضي ، وتبادل الاهمية بين

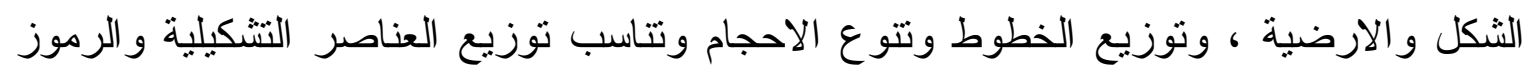
الكتابية 


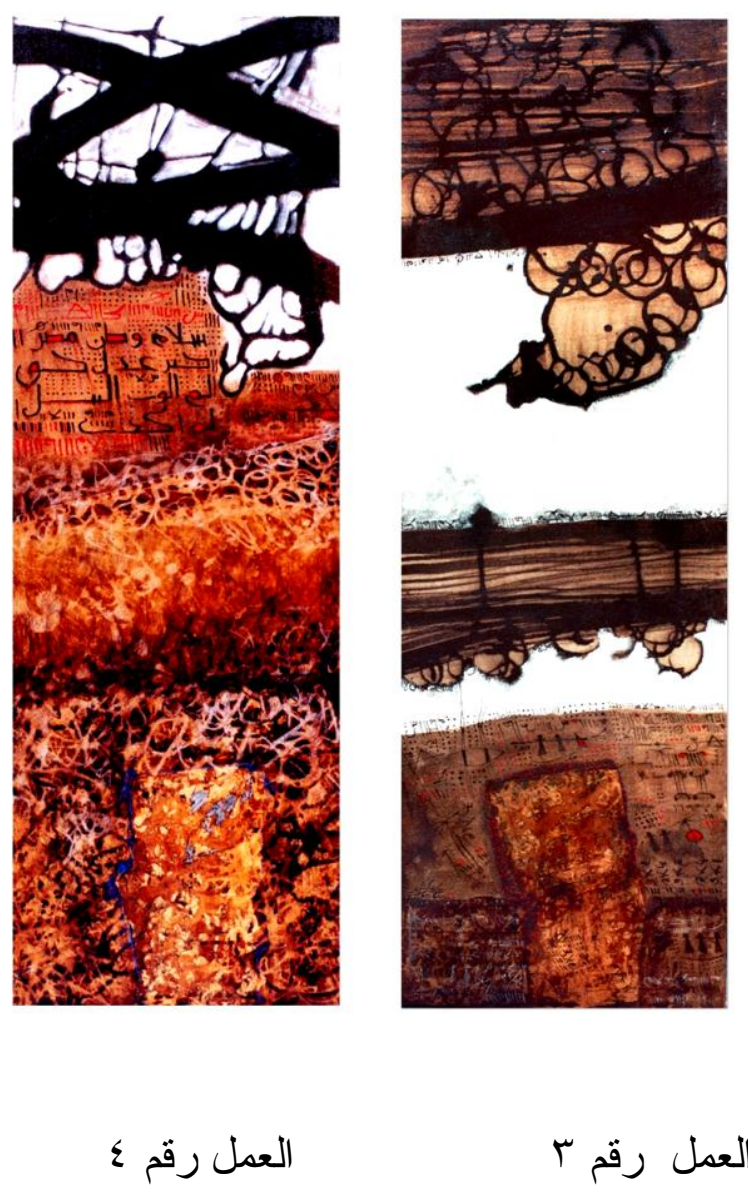

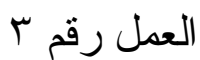

وفية الجمع ببين التلقائة في استخدامات الخطوط المتداخلة الافقية و الدائرية و البنائية الهندسية العقلانية للمساحات بالاضافة إلي در اسة النسبة الجمالية للعلاقة بين الثكل و الفر اغ الابيض دون الاخلال بالنسق البنائي للعمل الفني

(العمل رقم

وفية تتضح العلاقة بين تلك الخطوط العريضة الحادة ذات اللون الاسود علي ارضية بيضاء مع تلك الخطوط العضوية البسيطة ذات الالوان الفاتحة علي ارضية متوسطة اللون 


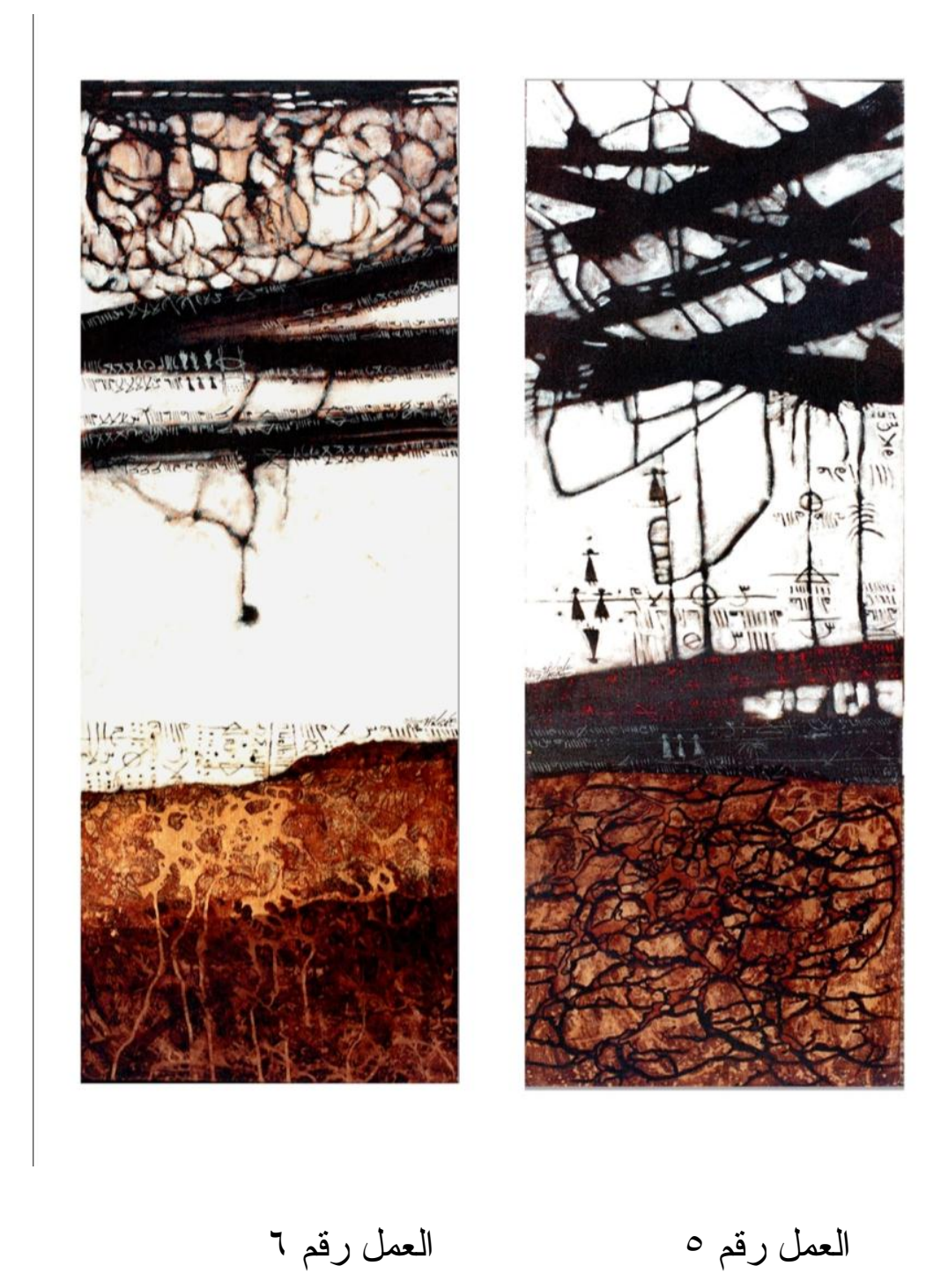

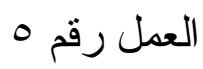

وفية يتضح طريقة الجمع بين الخطوط الحادة العريضة ذات اللون السوداء المتمركزة اعلي اللوحة وبين الخطوط العشو ائية العضوية ذات الحجم الضئيل و المتمركز في الجزء الاسفل ذا اللون البني عن طريق ثلك الخطوط الر اسية الممتدة من اعلي إلي اسفل و التي يحد من اندفاعها الخطين الأفقيين العريضين باللون المائل إلي الحمرةو البني القانم الممتد من ايسر اللوحة إلي الينها

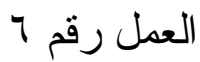
وفيها نري التداخل بين الخطوط الهندسية الافقية و الخطوط الدائرية العضوية ثم تقسيم اللوحة إلي اقسام ثلاث بربط بنها تلك الخطوط البسيطة التي رسمت بها الرموز الكتابية و الهندية 

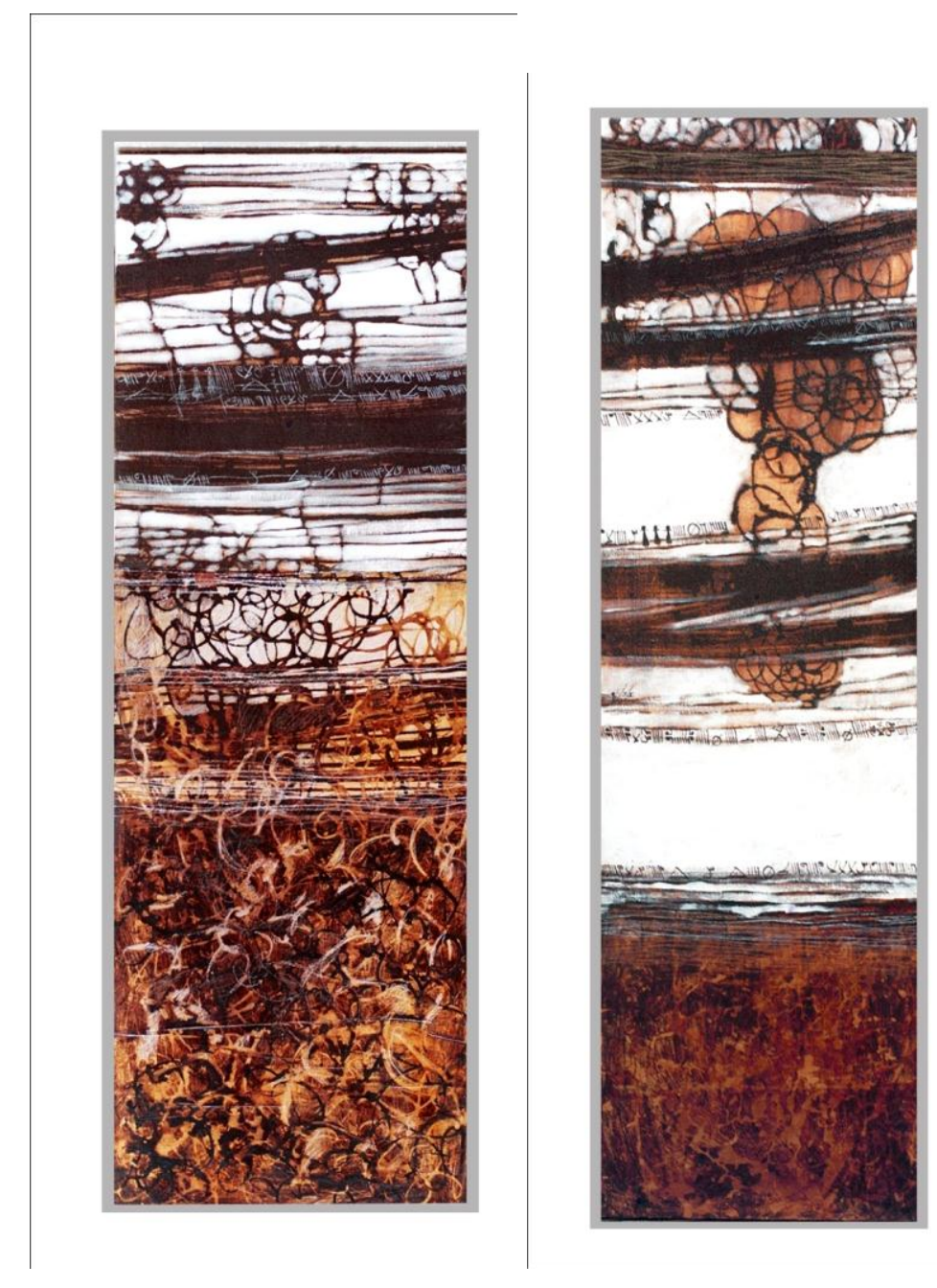

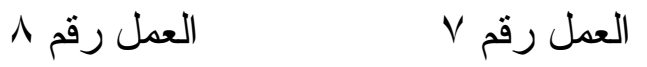

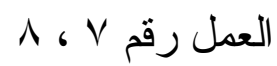

تتاكد فيها التداخلات بين الانو اعو الاحجام المختلفة ذات طرق الاداء المتتو عة بين الحركة الدائرية المنطلقة بتلقائة وسحب الفرشاة العريضة و التهشير ات و تلك التقسيمات الافقية لمسطح اللوحة و التوزيعات المتانقة للعناصر الفنية الكتابية و الشعبية و الهندسية 


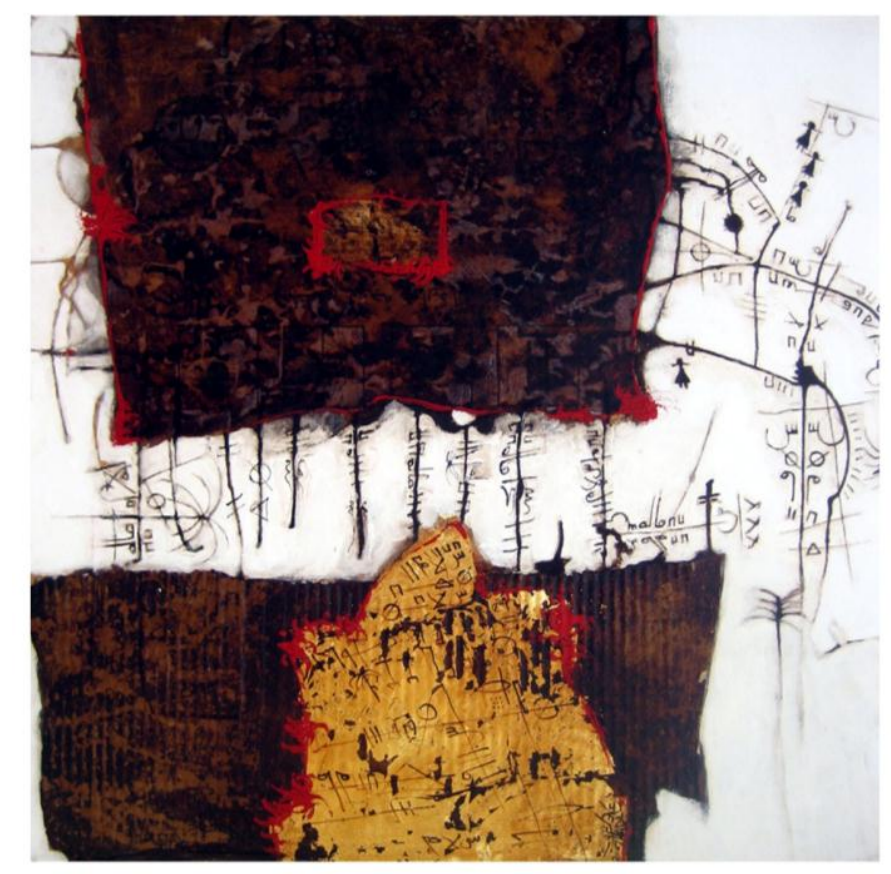

(العمل رقم 9

العمل رقم 9

وفية تحولت اللوحة إلي الثنكل المربع كما تماسكت الخطوط لتتحول إلي كتلنتين في اسفل و اعلي

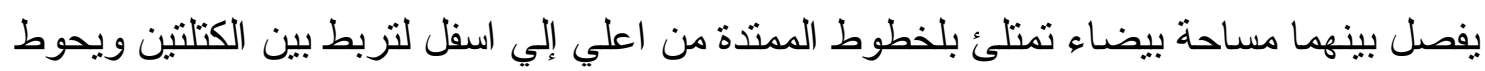

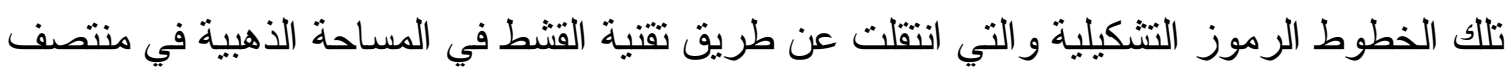
المساحة السفلي كذلك استخدام درجات اللون الاحمر بتبادل بين المساحة العليا و السفلي حتي تؤكد علي النز ابط بين العناصر 


\section{المجموعة الثاتية}

وفيها استمر الفنان علي الاستخدام التقني و الفني في المجموعة الاولي مضيفا اليها رؤي مستحدثة

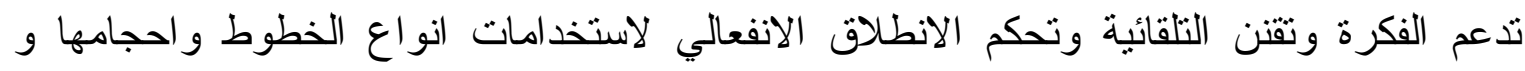
التوصل إلي بنية تشكيلية قائمة علي استاهام مجموعة من الاثكال تتتج عن طريق التظليل اللوني

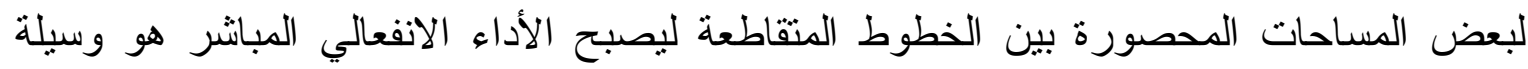
لاستدعاء رموز تتكيلية توصل اليه الباحث عن طريق دراسة طبيعة الاثكال التي تم انتاجها

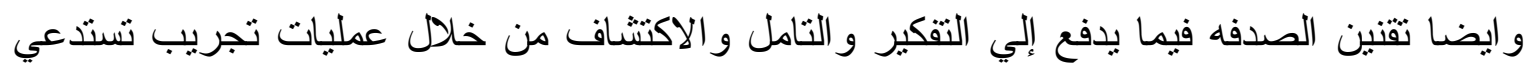
تتابعا منطقيا لعناصر العمل الفني ومفرداتة للوصول إلي نسق بنائي جديد خالص فائم علئ علي نو الد الد الاثكال من بعضها من بعض و هي أثنكال تكتسب حيويتها من قيمتها الارنباطيه وطاقتها التعبيرية

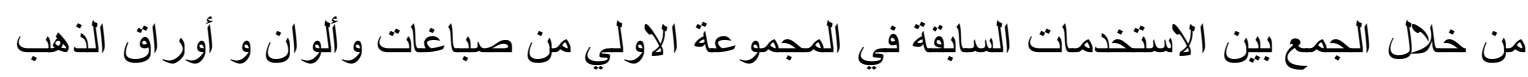

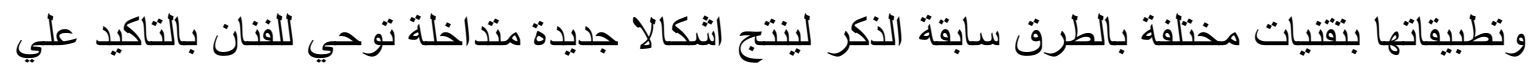
بعضها توحي للباحث بمجموعة من الرموز الجديدة المجردة أو المحورة أو المستحدثة

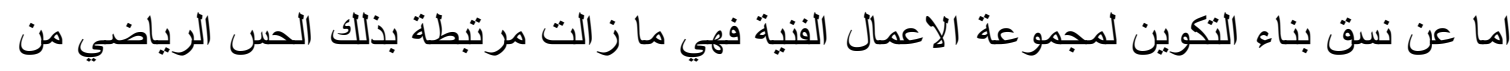
خلال اعادة الترتيب و التنظيم الذي اختلف من التقسيمات الافقية للتكوين إلي تكوينات اكثر تداخل

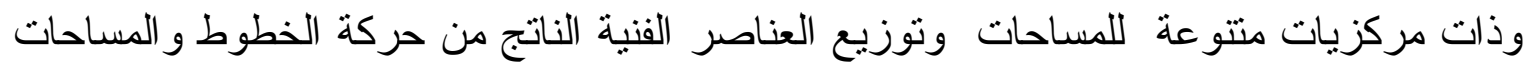

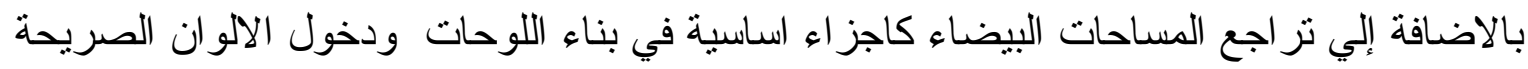
التي يغلب عليها الاحمر وبعض من الازرق مع درجات البني السيبيا مع استمرارية استخدام العناصر و المفردات التشكيلية المكملة لبنيت العمل الفني 


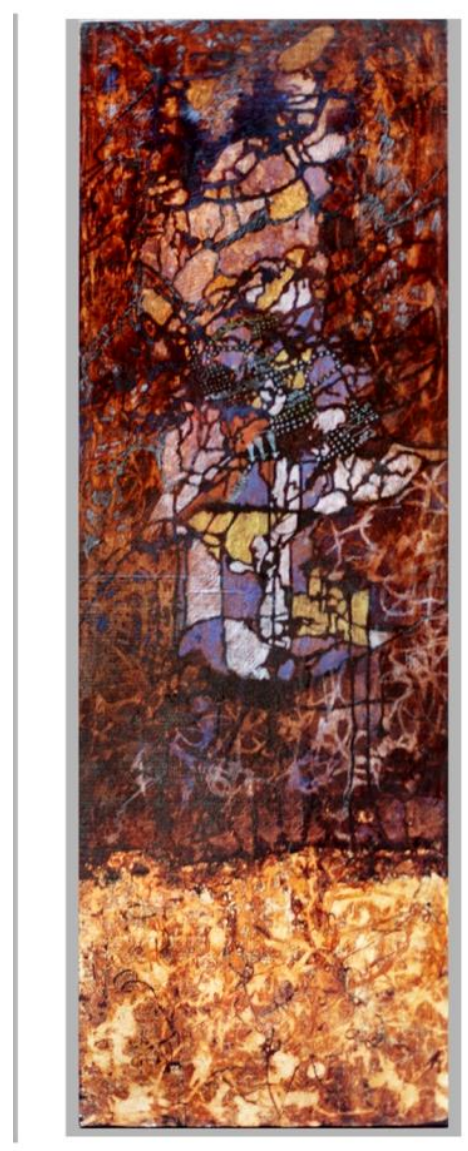

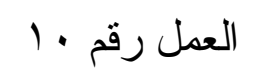

وفية استمر ارية للاستخدام الانفعالي المباثر للخطوط المنداخلة بالتقنيات السابقة وفيه تختفي

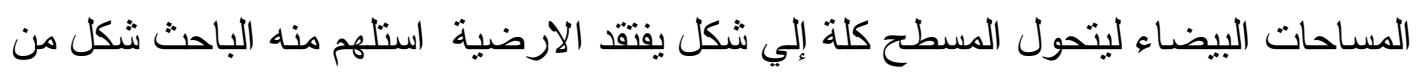

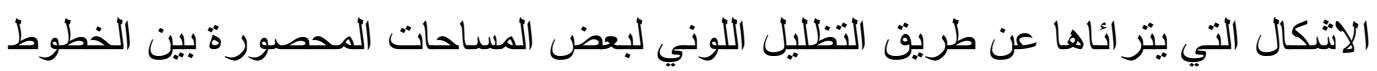

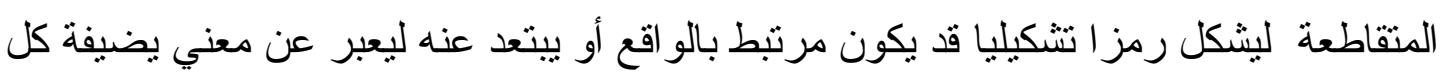
مشاهد للعمل 

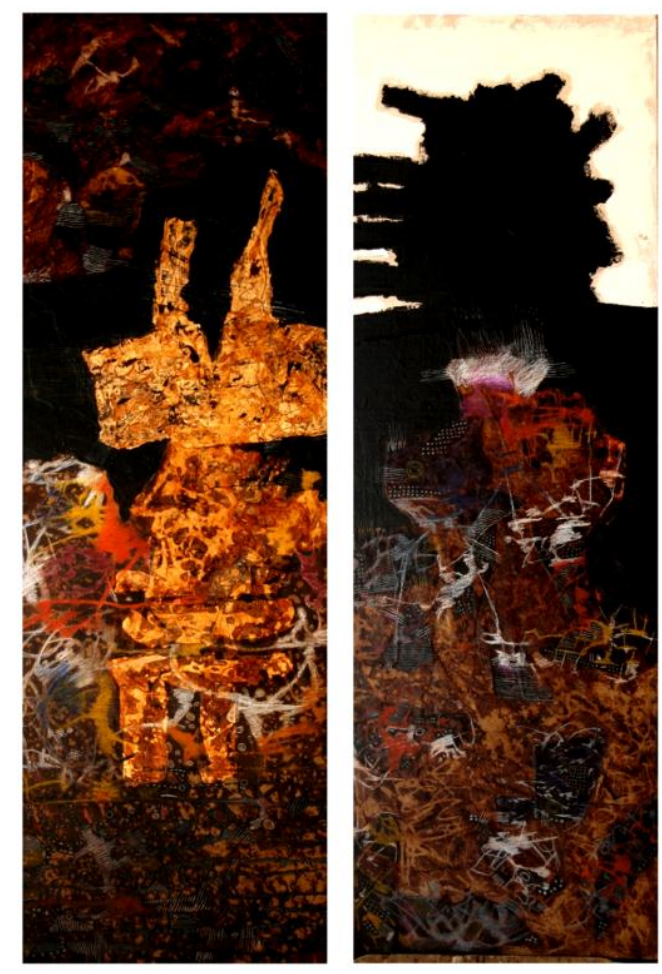

العمل رقم

العمل رقم 11

العمل رقم

استلهم الباحث من الخطوط اثكال اكدها عن طريق استخدام المساحات القاتمة وهي تميل إلي اثكال خيالية محاطة بمساحات بيضاء من اعلي وخطوط ملونة منتشابكة ومتقاطعة من اسفل وهي تمثل في ذاتها شكلا اخر منز اكب علي الاول وهو ما يسمح للمشاهد باعمال الذهن و البحث الجمالي و المشاركة الفعالة مع العمل الفني العمل رقم

اختلف الثكل المستوحي ليتكون من مساحات متداخلة من اللون الذهبي وهي محاطة بمساحات قاتمة محاطة باتشكال هلامية من درجات اللون البني من اعلي تزيد من بروز الثكل علي السطح إلي جانب تلاك الخطوط الملونة المنشابكة و المتقاطعة و التي تمثد علي الثكل نفسة 


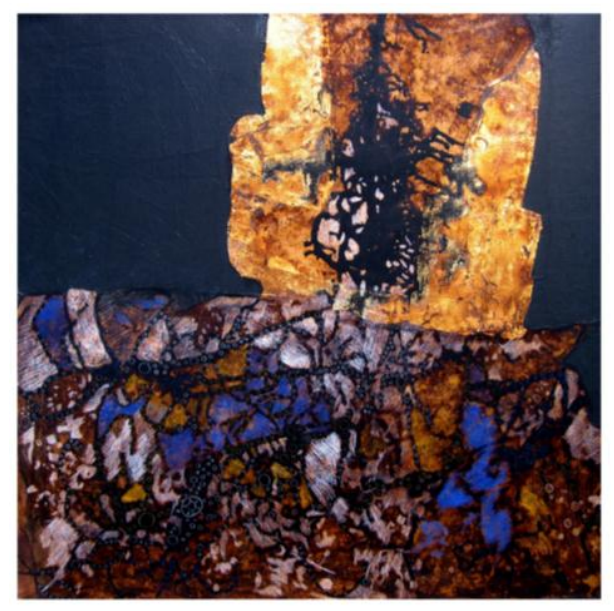

| (العمل رقم

$$
\text { (العمل رقم }
$$

اعتمد البناء التكويني للوحة علي تقسيم سطح اللوحة إلي نصفين افقيا وازن بينهما عن طرق معالجة

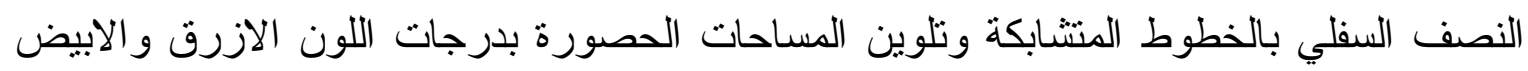

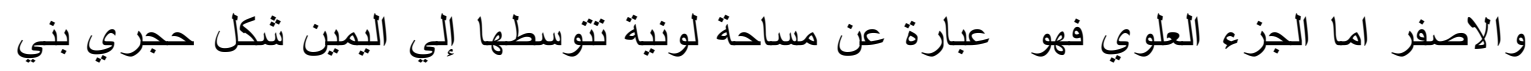
باللون الذهبي يظهر وكانة ثلاثي الابعاد

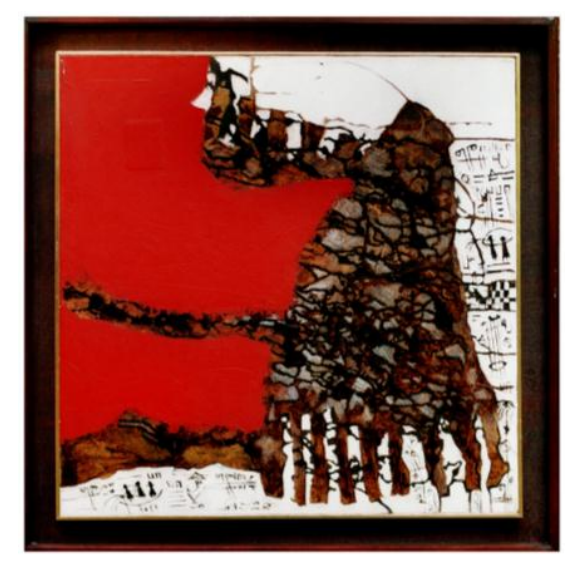

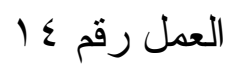

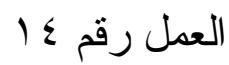

ينقسم العمل راسيا إلي ثلاثة اقسام اختلفت في طريقة الاداء وفي اللون ولكنها نوحدت عن طريق

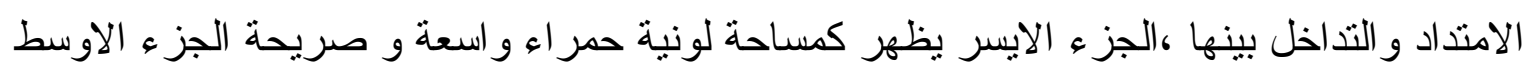


تم تشكيلها عن طريق توزيع الخطوط بنية اللون وهي توحي بشكل ايهامي رمزي اما المساحة الثالثة و هي بيضاء تمتد علي شكل حرف L استخدم فيها الرموز الكتابية والهندسية

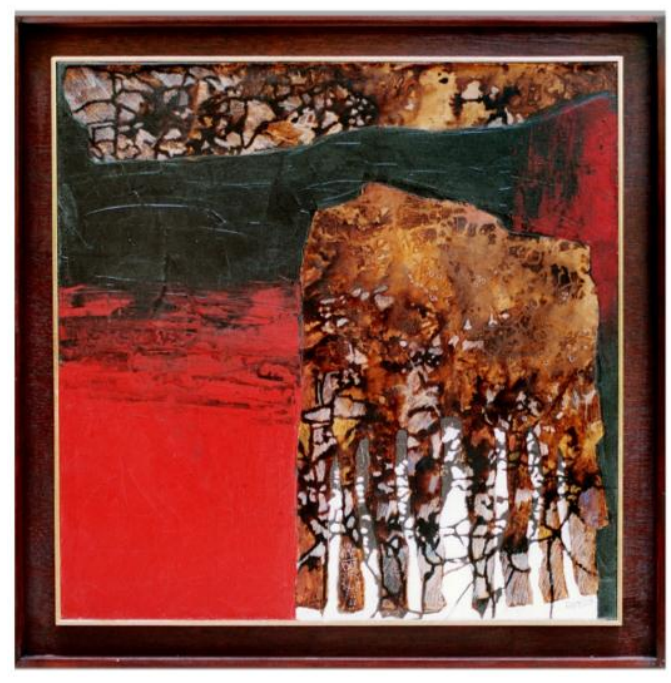

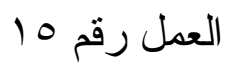

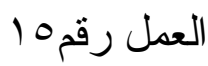

اختلف التتسيق الجمالي و التركيب البنائي للوحة واصبحت المساحات اكثر تعبيرا وايحاءا حيث انقسم العمل إلي ثلاثة اقسام اختلفت في طريقة الاداء وفي اللون ولكنها توحدت عن طريق الامتداد البصري بين الاقسام ،الجزء الايسر يظهر كمساحة لونية حمراء و اسعة يتذاخل معة اللون البني

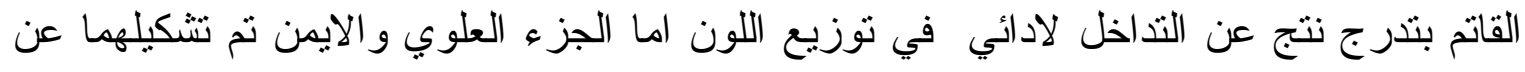
طريق توزيع الخطوط بنية اللون ليوحي الايمن بشكل ايهامي رمزي علي ارضية لبونية بيضاء 


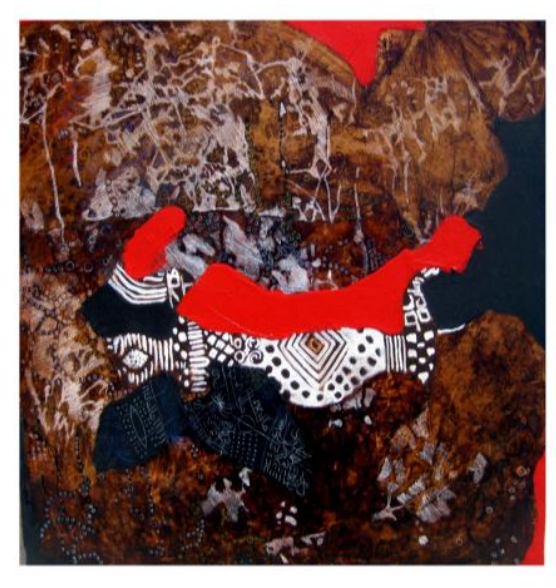

(العمل رقم 17

\section{العمل رقم}

وفية تنظيم بنائي اختلف في الثكل والايحاء فقد نم تصوير الثكل في منتصف اللوحة كمركز

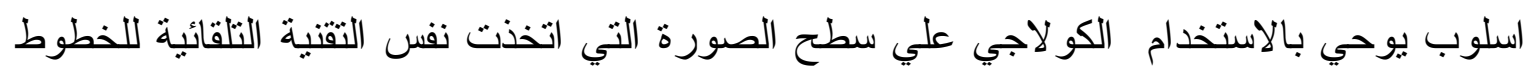

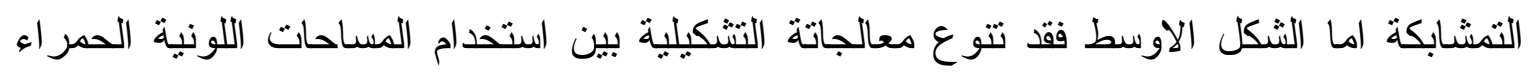
و السوداء الصريحة وبين المساحات البيضاء المشغولة برموز زخرفية افريقية 